

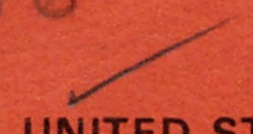

UNITED STATES DEPARTMENT OF THE INTERIOR

GEOLOGICAL SURVEY
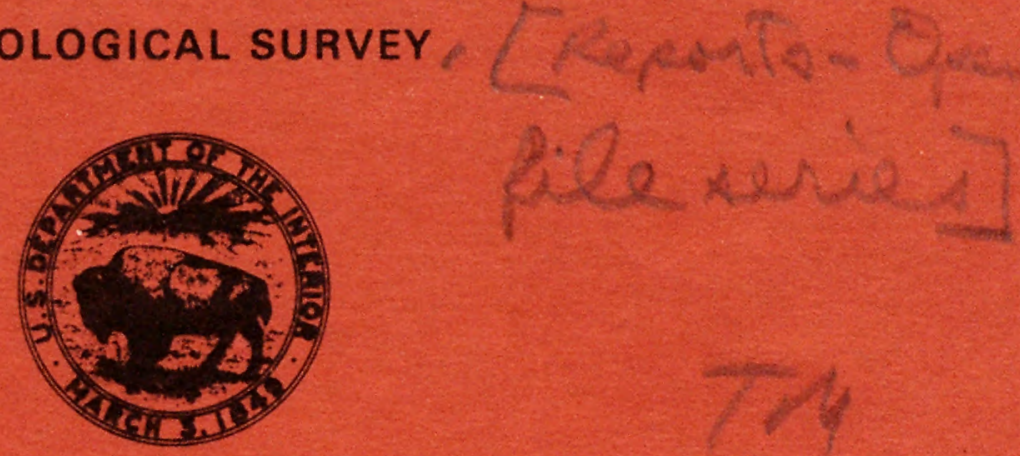

\title{
A Probabilistic Estimate of Maximum Acceleration in Rock in the Contiguous United States
}

\author{
by \\ S. T. Algermissen and David M. Perkins \\ U.S. Geological Survey
}

Open File Report $76 \cdot 416$

1976

This report is preliminary and has not been edited or reviewed for conformity with U.S. Geological Survey standards. 
<smiles>C1=CCCCCCCC1</smiles> 
$(200)$

R29o

$n 0.76-4 / 6$

\section{UNITED STATES DEPARTMENT OF THE INTERIOR \\ U.S. GEOLOGICAL SURVEY}

A Probabilistic Estimate of Maximum Acceleration in Rock

in the Contiguous United States

by

S. T. Algermissen and David M. Perkins

U.S. Geological Survey

Open-File Report 76-416

1976

This report is preliminary and has not been edited or reviewed for conformity with U.S. Geological Survey standards. 

Introduction

Theory

Construction of the model

Poisson process 9

Construction of seismic source zones-.................. 10

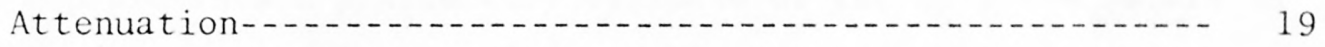

Special calculations for finite-length sources-....... 21

The hazard map- 23

Appropriateness of this map as a design motion map-...-. 24

The impact of geology on the map.... 26

Sensitivity to elemental assumptions-........ 29

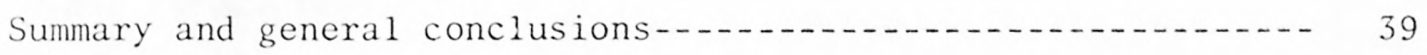

Acknowledgments-..... 41

References cited-..... 42

Figure captions-... 46 

This paper presents a probabilistic estimate of the maximum ground acceleration to be expected from earthquakes occurring in the contiguous United States. It is based primarily upon the historic seismic record which ranges from very incomplete before 1930 to moderately complete after 1960. Geologic data, primarily distribution of faults, have been employed only to a minor extent, because most such data have not been interpreted yet with earthquake hazard evaluation in mind.

The map provides a preliminary estimate of the relative hazard in various parts of the country. The report provides a method for evaluating the relative importance of the many parameters and assumptions in hazard analysis. The map and methods of evaluation described reflect the current state of understanding and are intended to be useful for engineering purposes in reducing the effects of earthquakes on buildings and other structures.

Studies are underway on improved methods for evaluating the relative earthquake hazard of different regions. Comments on this paper are invited to help guide future research and revisions of the accompanying map.

The earthquake hazard in the United States has been estimated in a variety of ways since the initial effort by Ulrich (see Roberts and Ulrich, 1950). In general, the earlier maps provided an estimate of the severity of ground shaking or damage but the frequency of occurrence of the shaking or damage was not given. Ulrich's map showed the distribution of expected damage in terms of no damage (zone 0), minor damage 
(zone 1), moderate damage (zone 2), and major damage (zone 3). The zones were not defined further and the frequency of occurrence of damage was not suggested. Richter (1959) and Algermissen (1969) estimated the ground motion in terms of maximum Modified Mercal1i intensity. Richter used the terms "occasional" and "frequent" to characterize intensity IX shaking and Algermissen included recurrence curves for various parts of the country in the paper accompanying his map.

The first probabilistic hazard maps covering portions of the United States were by Milne and Davenport (1969a). Recently, Wiggins, Hirshberg and Bronowicki (1974) prepared a probabilistic map of maximum particle velocity and Modified Mercalli intensity for the entire United States. The maps are based on an analysis of the historical seismicity. In general, geological data were not incorporated into the development of the maps. 
THEORY

Preparation of a probabilistic maximum acceleration map involves three main steps: (1) delineation of seismic source areas; (2) analysis of the statistical characteristics of historical earthquakes in each seismic source area; and (3) calculation and mapping of the extreme cumulative probability $F_{\max } t$ (a) of acceleration for some time, $t$. These steps are shown schematically in figure 1.

The general technique used here is essentially the same as that presented by Cornell (1968) with integrations replaced by discrete summations for flexibility in the representation of attenuation functions and source areas. The method used here was earlier applied to Utah and Arizona by Algermissen and Perkins (1972). For clarity the explanation that follows is given in terms of point sources. Extension to finite sources is described in a later section.

Three idealized seismic source areas are shown in figure 1A. These source areas are delineated on the basis of historical seismicity together with an evaluation of available geological evidence related to earthquake activity by methods to be detailed later.

After the zones are delineated, relationships of the form:

$$
\log N=a-b M
$$

are determined for each source area (see fig. 1B). $N$ is the number of earthquakes per unit time per unit area in a given magnitude range and 
$a$ and $b$ are constants to be determined. The temporal occurrence of earthquakes in the source area is characterized by the parameters of this equation, up to some maximum magnitude.

The future spatial occurrence of earthquakes in each source zone is assumed to be uniform throughout each source area. That is, if each seismic source area is divided into $\mathrm{n}$ small divisions (such as shown in fig. 1A) and if the number of earthquakes likely to occur in the magnitude range $\Delta M$ is $N_{\Delta M}$, then the number of earthquakes likely to occur in the magnitude range $\Delta M$ in each small division or block of a source area is:

$$
\frac{N_{\Delta M}}{n}
$$

Once the distribution of earthquakes likely to occur in each small division of the source is decided upon, the effect at each site due to the occurrence of earthquakes in each small division of the source can be computed using suitable acceleration attenuation curves such as those shown in figure $1 \mathrm{~B}$. In practice, the distribution of acceleration is computed for a large number of sites on a grid pattern (fig. 1A). The earthquake source areas are, of course, also included in the grid pattern.

From the distribution of acceleration at each site (part $\mathrm{C}$ of $\mathrm{fig}$. 1) it is possible to determine directly the expected number of times a particular acceleration is likely to occur in a given period of years at a given site, and, thereby, the maximum acceleration in a given number of years corresponding to any level of probability. 

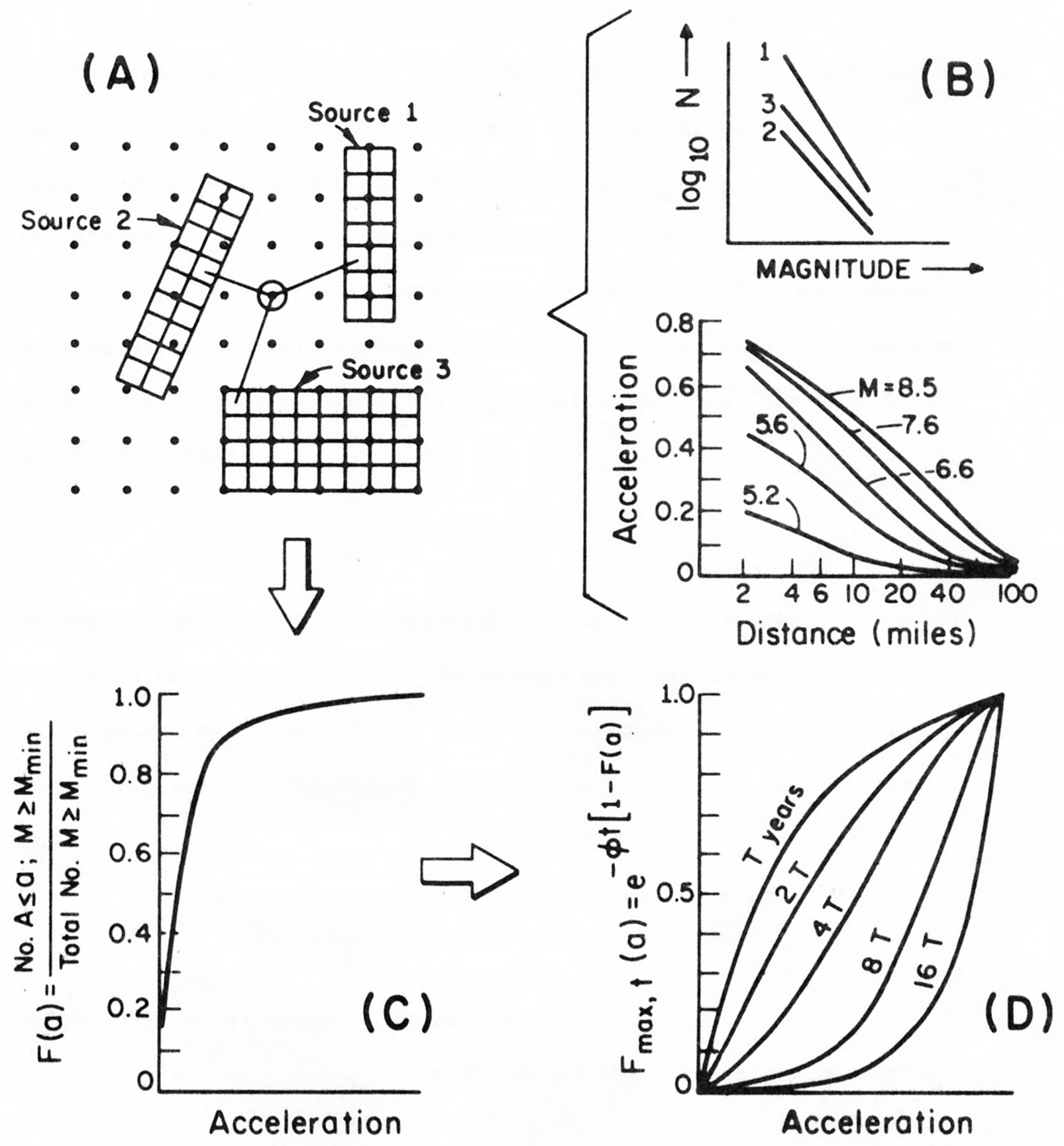

Figure 1.--Elements of the hazard calculation:
(A) Typical source areas and grid of points at which the hazard is to be computed.
(B) Statistical analysis of seismicity data and typical attenuation curves.
(C) Cumulative conditional probability distribution of acceleration.
(D) The extreme probability $F_{\max }, t(a)$ for various accelerations and
exposure times (T). 

As a result of the modeling process, then, we have the distribution of the expected number of occurrences of acceleration at each location where the hazard is to be calculated. For mapping purposes, as previously pointed out, the extreme probability $F_{\max } t(a)$ is calculated for all points of a grid and the results contoured.

To see how the peak acceleration corresponding to some extreme probability is calculated from the distribution of expected number of occurrences, consider the following development: Let the peak acceleration be a, then

$$
F(a)=P[A \leq a \mid M>M \text { min }]
$$

is the probability that an observed acceleration $\mathrm{A}$ is less than or equal to the value a, given that an earthquake with magnitude $M$, greater than some minimum magnitude of interest, has occurred. The calculation at a given grid point is performed for every acceleration a of interest using:

$$
F(a)=\frac{\text { expected number of occurrences with } A \leq a \text { and } M \geq M \text { min }}{\text { total expected number of occurrences }(M \geq M \text { min })^{\prime}}
$$

A typical $F(a)$ is shown in figure $1 \mathrm{C}$.

It is convenient here to also define the term return period as:

$$
R(a)=\frac{1}{1-F(a)}
$$

where $R(a)$ is the average number of events that must occur to get an acceleration exceeding a. The return period in years is given approximately by 


$$
R_{y}(a)=\frac{R(a)}{\text { Expected number of events per year }\left(M \geq M_{\text {min }}\right)}
$$

Assume $N$ independent events with accompanying accelerations $A_{i}$. The cumulative distribution of the maximum acceleration of the set of $\mathrm{N}$ accelerations is given by

$$
\begin{aligned}
& \begin{array}{r}
\mathrm{F}_{\max }(\mathrm{a})=\mathrm{P}[\text { The largest of the } \mathrm{N} \text { accelerations is less than or } \\
\text { equal to a] }
\end{array} \\
& =\mathrm{P} \frac{\text { each }}{\underline{\mathrm{a}}]} \text { of the } \mathrm{N} \text { accelerations is less than or equal to } \\
& =\underset{\text { pendent }}{P\left[A_{1} \leq a\right] P\left[A_{2} \leq a\right] \ldots P\left[A_{n} \leq a\right], \text { since the events are inde- }} \\
& =F(A)^{N} \text {, if the events are identically distributed }
\end{aligned}
$$

If $\mathrm{N}$ itself is a random variable

$$
\begin{aligned}
F_{\max }(a) & =F(a)^{\circ} \cdot P(N=0)+F(a)^{l} \cdot P(N=1)+\ldots+F(a)^{j} \cdot P(N=j)+\ldots \\
& =\sum_{j=0}^{\infty} F(a)^{j} P(N=j) .
\end{aligned}
$$

If $N$ has a Poisson distribution with mean rate $\lambda$,

$$
\begin{aligned}
F_{\max }(a) & =\sum_{j=0}^{\infty} F(a) j \cdot \frac{\lambda^{j} e^{-\lambda}}{j !}=e^{-\lambda} \sum_{j=0}^{\infty} \frac{(\lambda F(a))^{j}}{j !}=e^{-\lambda} e^{\lambda F(a)} \\
& =e^{-\lambda(1-F(a))}
\end{aligned}
$$

Now if $\lambda \pm \phi t$, where $\phi$ is mean rate of occurrence of earthquakes $M \geq M_{\min }$ per year and $t$ is number of years in a period of interest, then:

$$
F_{\max , t}(a)=e^{-\phi t(1-F(a))}
$$


In the program, a table of $\mathrm{a}$ and $\mathrm{F}(\mathrm{a})$ is constructed. For a particular $t=T, F_{\max } t^{(a)}$ is calculated, and the value of a for a given extreme probability, say $F_{\max }, t(a)=.90$, is found by interpolation.

Returning to the concept of return period, we obtain from (4) and (5):

$$
\begin{array}{ll} 
& \phi t(1-F(a))=\frac{t}{R_{y}(a)} \\
\text { thus, } & F_{\max , t}(a)=e^{-t / R_{y}(a)} \\
\text { and } & \ln \left(F_{\max , t}(a)\right)=-\frac{t}{R_{y}(a)}
\end{array}
$$

For estimating the hazard in the United States we have mapped the maximum acceleration with a 10 percent probability of being exceeded in 50 years. Using (12), we have

$$
\begin{aligned}
\ln (.90) & =-\frac{50}{R_{y}(a)} \\
\text { or } \quad & R_{y}(a)=\frac{50}{.1054} \simeq 475 \text { years }
\end{aligned}
$$

Thus, the return period for the accelerations we have mapped is about 475 years.

It may be useful to point out that using equation (11) and setting

$$
t=R_{y}(a)
$$

we have: $\quad F_{\max }, t(a)=e^{-1}=0.37$ 
Therefore the acceleration with a return period of $t$ years has a probability of

$$
1-F_{\max }, t(a)=1-0.37=0.63 \text { or } 63 \%
$$

of being exceeded in $t$ years. The point is that accelerations. (or any sther parameter) with a particular return period have a $63 \%$ probability of being exceeded within a time period equal to that return period. Because many people associate the acceleration with a return period of $R$ years with zero probability of exceedance in $R$ years, we think it is preferable to explicitly state the probability of exceedance and time $\mathrm{T}$ associated with a particular acceleration. In addition the earthquakes which produce the $\mathrm{R}$-year return period acceleration at a site may have recurrence intervals in the source region of one-third to one-tenth $R$. We hope that avoiding the use of return period will frustrate the toohasty identification with recurrence interval. 
This mapping of acceleration was begun as a kind of reconnaissance project to discover how a new treatment of the data and, to some extent, an integration of seismological and geological data would affect the evaluation of relative hazard in the United States. The model used is based on a number of assumptions and details of technique which affect, in varying degrees, the results obtained. The importance and influence of these assumptions and details of technique on the final results will be discussed in a later section. It should be noted at the onset that parameter uncertainty was not incorporated into the model. Rates of occurrence of earthquakes within seismic source areas, the boundaries of the source areas themselves, and the attenuation curves used in the analysis were all estimated deterministically. With the exception of attenuation curves, the effects of uncertainties in these parameters have, however, been estimated by variation of parameter techniques.

\section{Poisson process}

The assumption of a Poisson process for earthquakes in time does not do violence to the earthquake history insofar as that history affects the risk calculation. Large shocks closely approximate a Poisson process, while small shocks may depart significantly from a Poisson process. The ground motions associated with small earthquakes are of only marginal interest in engineering applications and consequently the Poisson assumption serves as a useful and simple model (Corne11, 1968). The crucial part of the assumption is that the earthquake 
events are independent and identically distributed. Once this assumption is made, most assumptions on the form of the discrete probability distribution for $N(p .6)$ yield roughly the same calculated extreme probabilities.

\section{Construction of seismic source zones}

The general principle used in the construction of the seismic source zones is that future earthquake occurrences are assumed to have the same general average time rate characteristics as the earthquakes of the past in the same overall region. It is further assumed that future earthquakes in a particular area may occur over somewhat more extended areas than indicated by historical data. We believe that this generalizing of past seismic activity is one of the most important functions of

a useful hazard map. The seismic source zones used in the computation of the acceleration map are shown in figure 2 .

In practice, the seismic source zones were drawn using the following general guidelines:

1. Areas of seismicity where shocks of maximum Modified Mercalli intensity $V$ or greater (magnitudes of about 4.0 or greater) have occurred were considered zones. For any given zone, the average distance from the epicenters to the boundary was chosen to be approximately the average separation distance for earthquakes of the maximum intensity found there, when these were sufficiently numerous to establish such a distance. If the maximum intensity earthquake in a source area only occurred once or twice, the distance between earthquakes of the next largest intensity was used. 
2. Zones such as described in (1) above were extended to include adjacent areas where evidence of Holocene faulting is present. A good example is the Salt Lake City, Utah, area where earthquake activity has been quite moderate, although significant seismicity is known southwest and north of Salt Lake City. However, faulting of probable Holocene age has been recognized from near the IdahoUtah border to approximately $100 \mathrm{~km}$ south of Utah Lake (Bucknam, oral commun., 1976; Morisawa, 1972; Hintze, 1972). For older faults, the zones described in (1) were extended to such a degree that the extension distance is about half the diameter of the source region found in (1). This type of extension was used in the Great Plains and Southern Rockies, where epicentral clusters could be associated with faults appearing on the tectonic maps of the United States.

3. In California where high seismicity can in general be associated with active faults, the faults or fault provinces rather than the epicenters were the primary guides in determining the zones. This generalization is also true to some extent for Nevada.

4. From (2) and (3), areas of known Quaternary faulting are generally within source zones, if the faulting is associated with at least low level historical seismicity. Except as noted above, Quaternary or older faulting not associated with significant historical seismicity (earthquakes with M.M. intensities V or greater) was not included within source areas. 
5. Isolated earthquakes which could not be associated with known faults or tectonic features were treated as seismic background. These were earthquakes with maximum intensities of VII or less in the midwest. It was assumed that they could occur over broad areas of the midwest not included in the source zones shown in figure 2. These isolated earthquakes produced acceleration levels below the lowest acceleration contour on our map.

Using these principles, the seismic history was generalized to produce zones which serve to reduce or eliminate the localized contour details found on hazard maps constructed using only historical seismicity (Milne and Davenport, 1969a,b; Wiggins and others, 1974; Liu and DeCapua, 1975). We also believe that this approach results in a more realistic appraisal of the hazard.

The following discussion presents some of the details of the construction of the zones in various sections of the country.

Northeast. --A number of seismicity "trends" in the Northeastern United States have been discussed, and attempts have been made to relate these trends with various tectonic structures. Woollard (1969) suggested trends along the St. Lawrence Valley, from Maine to Long Island, and along the Appalachians from Alabama to New Brunswick, Canada. Smith (1962, 1966), Leblanc and others (1971), and Diment and others (1972) discuss a trend striking northwest from Boston through Montreal and Ottawa. The difficulty with all of these seismic trends is that there does not appear to be any very conclusive evidence that associates any of these trends with tectonic elements or active faulting. The alignment of epicenters along the St. Lawrence Valley has numerous gaps (see 
Smith, 1966), and there does not appear to be compelling geologic evidence for such an alignment (Fischer and McWhorter, 1972; Sbar and Sykes, 1973). Woollard could find no particular relation between earthquakes in the Appalachians and any recognized tectonic segment, but Fox (1970) observed that in the southern Appalachians greater seismicity occurred where faults and intrusives are present. It has been suggested that the so-called Boston-Ottawa trend may be along an extension of the Kelvin seamount chain (Diment and others, 1972).

Unfortunately, we know of no clear evidence of Holocene faulting that has been associated with any of these seismic trends. Oliver and others (1970) found a number of smal1, post-glacial, high-angle faults extending north from New Hyde Park, New York and passing east of Lake Champlain and trending to the northeast in Quebec as far as St. Georges. They were unable to determine if the faults were of tectonic origin. Sbar and Sykes (1973) suggest that "the locations of earthquakes in eastern North America are controlled by unhealed faults or fault zones in the presence of a high deviatoric stress" and that the orientation of the faults with respect to the stress field may be a factor in determining when fault-strain release occurs.

Our seismic source zones in the northeast are based principally on the distribution of historical seismicity, since the available geological data provides no reliable guidelines for the association of seismicity with geologic structure. The Boston-Ottawa trend is represented by one continuous source area, since the seismicity is continuously distributed along the trend. The St. Lawrence Valley is broken up into several 
source areas based upon the historical data. This may prove to be incorrect since the areas of historically low seismicity may represent seismic gaps. Our representation of seismic source areas is, however, consistent with the historic seismicity and the state of knowledge of the relationship between geological structure and seismicity in the northeast.

Southeast.--Seismic source areas for the Southeastern United States were constructed using approximately the seismic source zones and rates of occurrences of earthquakes determined by Bollinger (1973). These zones reflect Bollinger's conclusion that epicenters in the southeast are not randomly distributed but occur in zones both parallel and transverse to the regional Appalachian structures. Our seismic source zone is consistent in strike with the strike of the fault plane of the November 22, 1974, shock near Summerville, South Carolina (Tarr, oral commun., 1976) and in areal extent with the recently discovered Holocene faulting near Augusta, Georgia (Prowe11 and others, 1975).

Midwest and Eastern Rockies.--Seismic source zones in the Mississippi Valley were modeled after those of Nuttli (1973). Zones in the remainder of the midwest were based principally on historical seismicity with attention to faulting and tectonic elements shown on the tectonic maps of the United States and North America (U.S. Geological Survey, 1962; King, 1969).

Arizona, Utah, Idaho, western Montana and Wyoming.--The zones in Utah and Arizona are based on earlier work (Algermissen and Perkins, 1972). The zones in Idaho, western Montana, and Wyoming coincide with the seismicity and tectonic trends. 
Pacific Northwest.--The earthquakes in zones 20 and 21 (fig. 2) were taken to have focal depths of about $60 \mathrm{~km}$. The known damaging earthquakes in these areas have occurred at about this depth. A recent, detailed study may be found in Hopper and others (1975). The configuration of the zones is based on historical seismicity, primarily from studies by Stepp (1971) and Hopper and others (1975).

California and Nevada.--The patterns of source zones in California and Nevada are controlled largely by the patterns and orientations of fault systems which are known to have had Holocene faulting and, in many cases, historical faulting. The distribution and age of movement of faults in California was taken from the provisional faulting map of California (Kahle, 1971) and in Nevada from the "Tectonic Map of the United States (U.S.G.S., 1962) and Ryall and others (1966). Much more geological data and a higher rate of seismic activity are present in California and Nevada than in the remainder of the country. Sufficient data exists to map these areas at scales larger than the scale presented here. With the exception of the San Andreas, Owens Valley, and a portion of the Garlock fault systems, no attempt was made to isolate single faults or fault systems in a particular zone. Rather, systems with parallel or subparallel strikes, similar rates of earthquake occurrence during historical times, and similar potential for large shocks were treated as single zones.

General Comments on the Seismic Source Zones.--An overview of the zones (fig. 2) shows that zones in the midwest and east are, for the most part, larger and show less detail than zones in the Western States. 
This is principally a reflection of the paucity of data relating faults to earthquakes in the east and midwest. It also reflects a general rule of hazard mapping. If relationships between geologic structure and earthquake occurrence are well known, detailed hazard maps can be prepared, but if little is known about these relationships, the resulting hazard map will be quite generalized.

Maximum magnitude earthquake in each zone.--The maximum magnitude earthquake in each zone was taken to be the maximum known or estimated from the historical record. However, in California, the historical seismicity record was supplemented with evidence of historical faulting using a fault length-magnitude relationships (Bonilla, 1967). The maximum magnitudes assumed for al1 zones are given in table 1.

Rates-of-occurrence.--The expected seismicity for each source zone was developed from an analysis of the historical seismicity of the region in which the individual source lies using as basic data the catalog in Hays and others (1975). In general, the regional analysis was performed by fitting the relationship $\log \mathrm{N}=\mathrm{a}+\mathrm{b}_{\mathrm{I}} \mathrm{I}_{\circ}$, where $\mathrm{N}$ is the number of yearly occurrences with maximum intensity $I_{0}$, where $I_{0}$ is either the observed historical maximum intensity, or is determined from the observed magnitude by the relation (Gutenberg and Richter, 1942)

$$
M_{C}=1.3+0.6 I 。
$$

where $M_{C}$ is the magnitude corresponding to $I_{0}$ in equation (14). If the observed $M$ lies between $M_{c}-0.3$ and $M_{c}+0.3$, intensity $I_{\circ}$ is assigned. Equation (14) is nearly the same as that derived by Algermissen and others (1969) using a much larger sample than the one available to Gutenberg and Richter. 
Table 1.--Seismic parameters for source zones

\begin{tabular}{|c|c|c|c|c|}
\hline $\begin{array}{c}\text { Zone* } \\
\text { No. }\end{array}$ & $\begin{array}{l}\text { No. of Modified } \\
\text { Mercalli Maximum } \\
\text { Intensity V's } \\
/ 100 \mathrm{yrs}\end{array}$ & ${ }^{b}{ }_{I}$ & $\begin{array}{l}\text { Maximum } \\
\mathrm{I}_{0}\end{array}$ & $\underset{M_{C}}{M a x i m u m}$ \\
\hline 1 & 245.2 & -.50 & $x$ & 7.3 \\
\hline 2 & 110.0 & -.40 up to $X I$ & & \\
\hline & & then flat & XI I & 8.5 \\
\hline 3 & 27.2 & -.45 & XI & 7.9 \\
\hline 4 & 75.1 & -.45 & XI & 7.9 \\
\hline 5 & 14.9 & -.50 & $x$ & 7.3 \\
\hline 6 & 44.4 & -.45 & $X I$ & 7.9 \\
\hline 7 & 299.6 & -.53 & VIII & 6.1 \\
\hline 8 & 7.3 & -.49 & VI & 4.9 \\
\hline 9 & 208.0 & -.40 & $X I$ & 7.9 \\
\hline 10 & 125.0 & -.51 & VIII & 6.1 \\
\hline 11 & 80.1 & -.53 & VIII & 6.1 \\
\hline 12 & 43.0 & -.43 up to XI & & \\
\hline & & then flat & XII & 8.5 \\
\hline 13 & 99.4 & -.45 & $X I$ & 7.9 \\
\hline $14 \therefore$ & 34.9 & -.45 & $X I$ & 7.9 \\
\hline 15 & 0.0 & -.53 & VIII & 6.1 \\
\hline 16 & 33.9 & -.50 & $\mathrm{x}$ & 7.3 \\
\hline 17 & 223.0 & -.45 & XI & 7.9 \\
\hline 18 & 2.8 & -.50 & $X$ & 7.3 \\
\hline 19 & 613.6 & -.52 & $\mathrm{X}$ & 7.3 \\
\hline 20 & 14.8 & -.29 & VI II & 7.1 \\
\hline 21 & 79.8 & -.59 & VII & 5.5 \\
\hline 22 & 80.1 & -.76 & VI & 4.9 \\
\hline 23 & 12.7 & Not applicable & V & 4.3 \\
\hline 24 & 6.0 & - do--...... & V & 4.3 \\
\hline 25 & 8.5 & -.59 & VII & 5.5 \\
\hline 26 & 137.1 & -.72 & VI & 4.9 \\
\hline 27 & 99.9 & -.67 & VII & 5.5 \\
\hline 28 & 35.3 & -.32 & IX & 6.7 \\
\hline 29 & 90.4 & -.36 & $X$ & 7.3 \\
\hline 30 & 10.5 & -.26 & VII & 5.5 \\
\hline 31 & 84.6 & -.63 & VII & 5.5 \\
\hline 32 & 17.0 & -.56 & VI & 4.9 \\
\hline 33 & 126.8 & -.56 & IX & 6.7 \\
\hline 34 & 71.0 & -.56 & VII & 5.5 \\
\hline 35 & 23.0 & -.56 & VIII & 6.1 \\
\hline 36 & 15.3 & -.54 & VII & 5.5 \\
\hline 37 & 15.6 & -.31 & VIII & 6.1 \\
\hline 38 & 31.1 & -.54 & VII & 5.5 \\
\hline 39 & 21.5 & -.54 & VII & 5.5 \\
\hline 40 & 2.7 & -.40 & VI & 4.9 \\
\hline
\end{tabular}


Table 1.--Seismic parameters for source zones--continued

\begin{tabular}{|c|c|c|c|c|}
\hline $\begin{array}{l}\text { Zone* } \\
\text { No. }\end{array}$ & $\begin{array}{l}\text { No. of Modified } \\
\text { Mercalli Maximum } \\
\text { Intensity V's } \\
/ 100 \text { yrs }\end{array}$ & ${ }^{b}{ }_{I}$ & $\begin{array}{l}\text { Maximum } \\
\mathrm{I}_{0}\end{array}$ & $\begin{array}{c}\text { Maximum } \\
{ }_{\mathrm{C}}\end{array}$ \\
\hline 41 & 27.6 & Not applicable & V & 4.9 \\
\hline 42 & 11.1 & -.40 & VI & 4.9 \\
\hline 43 & 23.0 & Not applicable & V & 4.3 \\
\hline 44 & 13.8 & -- do $-\cdots-----$ & V & 4.3 \\
\hline 45 & 6.7 & -.31 & VI I I & 6.1 \\
\hline 46 & 2.7 & -.40 & VI & 4.9 \\
\hline 47 & 2.7 & -.40 & VI & 4.9 \\
\hline 48 & 14.7 & -.54 & VII & 5.5 \\
\hline 49 & 10.3 & Not applicable & V & 4.3 \\
\hline 50 & 4.6 & -- do --------- & V & 4.3 \\
\hline 51 & 7.4 & -.53 & VI & 4.9 \\
\hline 52 & 13.0 & -.40 & VI & 4.9 \\
\hline 53 & 9.3 & -.24 & VIII & 6.1 \\
\hline 54 & $21: 2$ & -.55 & VII & 5.5 \\
\hline 55 & 1.7 & Not applicable & V & 4.3 \\
\hline 56 & 5.7 & -.53 & VI & 4.9 \\
\hline 57 & 7.8 & -.55 & VI I & 5.5 \\
\hline 58 & .6 & -.50 & VII & 5.5 \\
\hline 59 & 16.0 & -.50 & VIII & 6.1 \\
\hline 60 & 16.0 & -.50 & VI I I & 6.1 \\
\hline 61 & 84.5 & -.50 & X & 7.3 \\
\hline 62 & 22.0 & -.50 & VI I I & 6.1 \\
\hline 63 & 22.1 & -.64 & VIII & 6.1 \\
\hline 64 & 54.4 & -.59 & VI I I & 6.1 \\
\hline 65 & 19.9 & -.33 & X & 7.3 \\
\hline 66 & 13.0 & -.59 & VII I & 6.1 \\
\hline 67 & 7.8 & -.59 & VII & 5.5 \\
\hline 68 & 69.1 & -.67 & VIII & 6.1 \\
\hline 69 & 117.6 & -.59 & IX & 6.7 \\
\hline 70 & 33.5 & -.65 & VI I I & 6.1 \\
\hline 71 & 21.7 & -.49 & $x$ & 7.3 \\
\hline
\end{tabular}

*The zones are shown in figure 2 . 
The historical observed yearly rates for each intensity level were calculated by using the number of earthquakes occurring in the period of time during which it was judged that the historical record was complete. The general technique has been described by Algermissen (1969). In every case, obvious aftershocks were removed from the data. Smoothed rates were obtained by fitting

$$
\log \mathrm{N}_{\mathrm{c}}=\mathrm{a}+\mathrm{bM} \mathrm{c}_{\mathrm{c}}
$$

where $\mathrm{N}_{\mathrm{c}}$ is the number of earthquakes occurring with magnitudes $\mathrm{M}_{\mathrm{c}} \pm 0.3$. Outside of California the fitting was done by linear least squares regression of $\log \mathrm{N}_{\mathrm{C}}$ on $\mathrm{M}_{\mathrm{C}}$. However, in California, the minimization criterion was a "nearly-minimum" sum of chi-square values based on the observed vs fitted $N_{C}$ 's. (The results are similar to those given by weighted least squares, with weights equal to the observed $\mathrm{N}_{\mathrm{c}}{ }^{\prime} \mathrm{s}$. )

A single $\log N_{c}$ relationship (equation 15 ) was fit to the seismicity data (adjusted for completeness) for any region under consideration. The seismicity of each source zone within the region was allocated from the seismicity of the entire region in proportion to the smoothed numbers of observed earthquake in each intensity range in each source zone.

\section{Attenuation}

Two attenuation relationships were used for the acceleration calculations. West of longitude $105^{\circ}$ the attenuation relationships for acceleration in rock developed by Schnabel and Seed (1973) were used without modification. However, as calculations were performed for 
magnitudes down to $M=4.3$, a curve for a magnitude below this was needed. The curve for $M=4.2$ was calculated by fitting the Schnabel and Seed curves analytically and substituting for $M=4.2$. All shocks in this western area were considered to have focal depths consistent with the Schnabel and Seed curves. For source zones 20 and 21, the earthquakes were assumed to have depths of about $60 \mathrm{~km}$ and attenuation curves were developed (Algermissen and Perkins, 1976) that are consistent with acceleration data recorded during the Apri1 13, 1949 and Apri1 29, 1965 earthquakes in that area. For the area east of $105^{\circ}$ longitude it was found that the Schnabel and Seed curve for $M=7.6$ was consistent to a distance of about $50 \mathrm{~km}$ with the acceleration attenuation curve $M=7.6$ suggested by Nutt1i (1973) for the Central United States. Beyond this distance, the Nuttli curve attenuates at a slower rate. Curves for the east and midwest for the other magnitudes were then drawn tangent to the Schnabel and Seed curves, taking the same general shape as the Nutt1i curve. The resulting attenuation curves used are shown in figure 3 . For an acceleration of $.01 \mathrm{~g}$ and earthquakes greater than magnitude 6.6, the shaken area in the east is 10 times that in the west. At .04 $\mathrm{g}$ the ratio of the shaken areas is 4 or 1 ess. At $.1 \mathrm{~g}$ the ratio is 1.4 or 1ess. The general effect is to extend the shaken area beyond the source boundary an additional several tens of kilometres further in the East than in the Western United States.

The attenuation curves are for maximum horizontal accelerations in rock. This should be understood to mean accelerations in material having a shear wave velocity of between 0.75 and $0.90 \mathrm{~km} / \mathrm{sec}$ (Seed, 


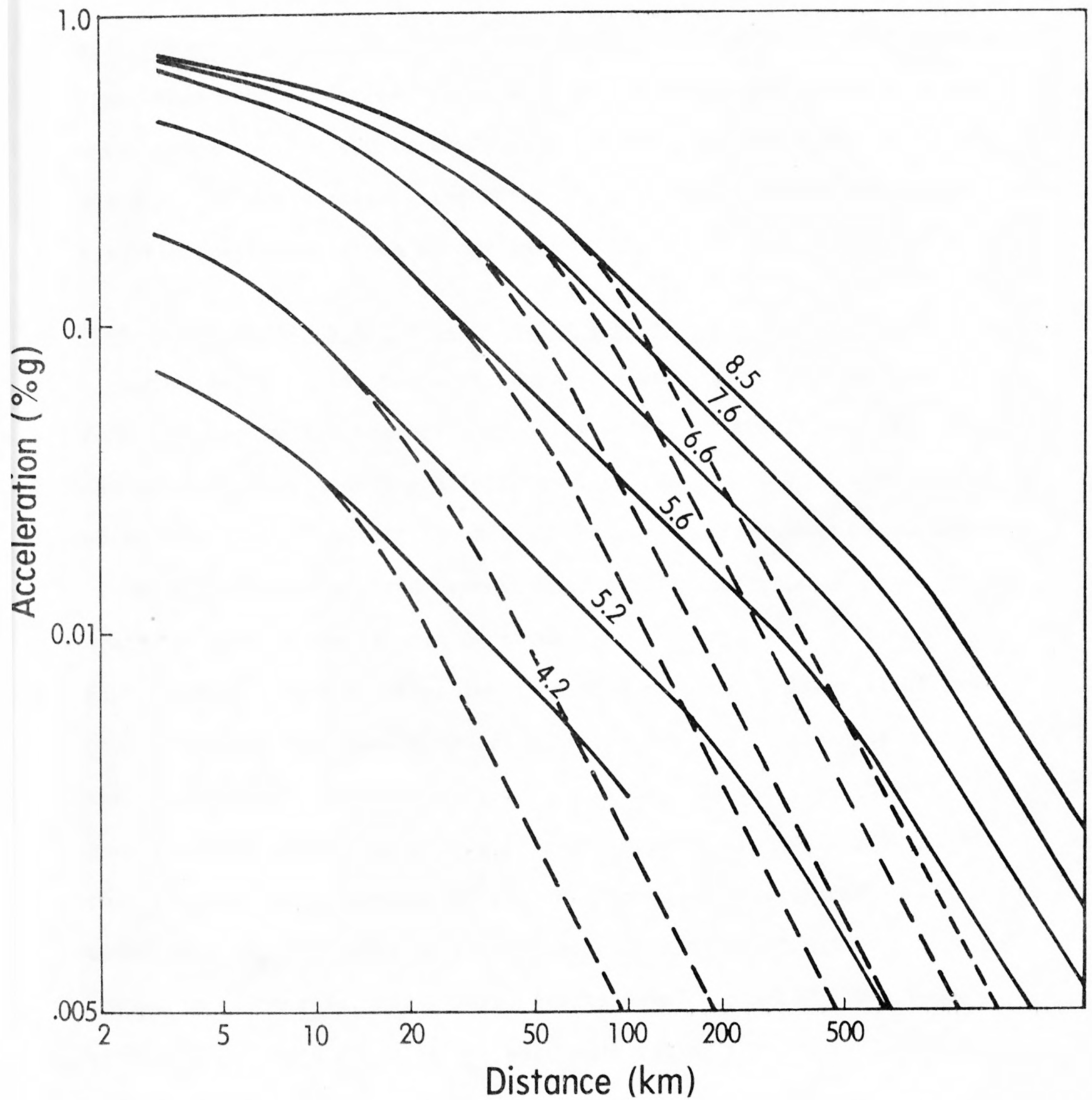

Figure 3.--Acceleration attenuation curves. The solid lines are curves used for the eastern region (see text for definition). The dashed lines together with solid lines at close distances are the attenuation curves used for the western region and are taken from Schnabel and Seed (1973). 

oral commun., 1976). It should be clearly understood that site materials other than rock as defined here, will result in accelerations that may have maximum values two to three times larger than the values shown on our map. In a few cases, site materials may result in accelerations slightly lower than shown on our map.

\section{Special calculations for finite-length sources}

Most seismic risk computer programs assume point attenuation functions (no matter whether from point, line, or areal sources). It can be shown that modeling a long-faulting earthquake by a series of point sources will result in underestimating the frequency of occurrence of large accelerations and overestimating the occurrence of small accelerations near the fault. In particular, if a particular section of fault breaks over its entire length with a recurrence interval of less than 475 years, the map should display (if this is the largest event) the acceleration isoseismals from this event. On the other hand, if such an event happens with a recurrence interval of, say, 4,750 years, the frequency of occurrence of the corresponding accelerations will not contribute significantly to the 475 -year return period motion. Accordingly, in California, where large events have relatively short recurrences, the hazard calculations were made taking the finite-length-fault effect into account.

For this purpose special acceleration attenuation curves were constructed at 0.6 magnitude unit intervals such that the acceleration attenuated perpendicular to the strike of the fault over the length of 
faulting assumed. At the two ends of the assumed fault break, the acceleration isoseismals were semi-circles. The length of the fault for each $M_{C}$ was given by the Bonilla (1967) regression of fault length on magnitude.

The effect of using a two-dimensional earthquake mechanism rather than a point source was to increase the calculated extreme accelerations over from those calculated using a point source. Differences in acceleration using the two methods ranged from 100 percent near the San Andreas and Owens Valley faults, to 40 percent in southern California to negligible in regions in which high magnitude earthquakes occurred with only long recurrences. Because the recurrence intervals along the San Andreas and Owens Valley faults are relatively short, the map acceleration values here are essentially those given by the Schnabel and Seed attenuations for $M=8.5$ events. For southern California and the Garlock fault area, the map values are governed by recurrences for somewhat smaller events. In these areas, this calculation was made using parallel finite faults with the same strike as the known faults in the area. 
The acceleration (given in percent of the acceleration of gravity) in hard rock with 90 percent probability of not being exceeded in 50 years is shown in figure 4. That is, there is only a 10 percent probability of these values being exceeded in 50 years. The map has the following general features.

1. The contour levels range from $.04 \mathrm{~g}$ to $.60 \mathrm{~g}$. Below the $.04 \mathrm{~g}$ contour level the ground shaking effects are largely controlled by earthquakes with magnitudes of 4.0 or less. Events of this size are incompletely recorded and it is difficult to estimate the recurrence rates for earthquakes of these magnitudes or smaller. Furthermore, it is likely that suitable attenuation functions will not produce accelerations larger than $.04 \mathrm{~g}$ except in the imnediate vicinity of the event. This limits their impact in the hazard calculation. In those regions of the map below the $.04 \mathrm{~g}$ contour, wind loading of structures is expected to be the governing factor in the design of structures, so that earthquake shaking, at the level of hazard assumed, is not 1ikely to be important.

The highest acceleration contour encloses the northern and central portion of the San Andreas fault and the Owens Valley fault, in which the recurrence interval of magnitude 8.5 events is less than 500 years. Within the $.60 \mathrm{~g}$ contours the maximum values are those given by the $M=8.5$ curve for acceleration at close distances, that is, about $0.80 \mathrm{~g}$. 
2. The regions in the Eastern United States which have experienced reasonably large damaging earthquakes in the past are outlined by the $.10 \mathrm{~g}$ contour (Charleston, New England, New Madrid). These values are governed by the much lower recurrence rates of earthquakes in these regions, compared to those of the Western United States.

3. Regions in the United States where intensity VII's or less have been experienced as isolated events generally lie in the below 0.04 $g$ portion of the map. This does not mean that damaging events cannot occur here, but only that for any given point in those regions there is no more than 10 percent likelihood that accelerations larger than $0.04 \mathrm{~g}$ will be experienced in 50 years.

\section{Appropriateness of this hazard map as a design motion map}

1. A single parameter such as a probabilistic estimate of maximum acceleration, which we have mapped, obviously does not provide all of the information necessary to describe the characteristics of strong ground motion that are important in the earthquake design of structures. Nevertheless, a wide range of structures can and have been designed to be earthquake resistant using peak acceleration as the basic ground motion data. Attention should be called to the current work of the Applied Technology Council (1976) on the development of comprehensive seismic design provisions applicable to building codes.

2. For structures in which acceleration is used as a design parameter, maximum acceleration probably is related to "effective" acceleration by some simple factor. 
3. For structures which should remain operable after large, damaging earthquakes, the 10 percent exceedance probability in 50 years seems reasonable and yields, in general, more conservative design accelerations than normally used in current practice.

4. For buildings for which velocity or response velocity may be a better design parameter, the relative hazard may appear too low at distances 50-300 km from active source regions. However, a recent study by Seed and others (1975) indicates that the ratio of maximum velocity to maximum acceleration $\left(\mathrm{v}_{\max } / \mathrm{a}_{\max }\right)$ obtained from strong motion records varies only between 22 and 29 for rock sites. Thus it appears that it might be possible to derive a useful velocity map from an acceleration map in a straightforward manner.

5. In a similar manner, for structures for which displacement may be a better design parameter, one might expect that the hazard extends much farther than shown on this map because displacement attenuates even more slowly than velocity. In addition, the levels of motion causing damage may be 1ow. For this reason it is difficult to provide a rule-of-thumb for the correspondence between this acceleration map and the design levels of displacement-designed structures.

6. For structures for which very low exceedance probabilities are appropriate (nuclear reactors where the public hazard may be very great or power plants and telephone exchanges where the economic impact of loss of service will be severe), it should be clear that this map indicates only a relative idea of the hazard--the design 
motions will be higher for much smaller exceedance probabilities. In those regions where seismicity is lower than in California, the accelerations shown on this map vary with return period according to the very approximate rule: the level of motion doubles as the return period increases by 5 (exceedance probability decreases by 5). Our map shows accelerations with exceedance probabilities of 10 percent in 50 years. Certain facilities such as nuclear power plants may require designs adequate for accelerations with exceedance probabilities no larger than 0.5 percent in 50 years. Using our seismic source zones and input parameters to produce a maximum acceleration map for 50 years at the 99.5 percent probability level ( 0.5 percent change of exceedance) will in every case result in higher accelerations than the present map. Furthermore, the accelerations will be proportionately higher outside of California than within California.

The impact of geology on the map

We have attempted to utilize geological data in the process of defining the seismic source zones. It remains to assess the impact of our use of the available geological data on the definition of the source areas and the resulting hazard map.

Unfortunately, the kind of geological information that is useful in hazard mapping is generally not available. Most geologists in the past have not concerned themselves sufficiently with crustal deformation during the Pleistocene and Holocene epochs. Analyses of faulting in late geologic time has been incidental to other concerns. Much of it 
has not been accurate enough for hazard evaluation even on a regional basis. Even though the amount of useful geological data available is small over the country as a whole, and virtually nonexistent in the eastern United States, we feel that the geological data we have used has improved the hazard map. An example is the Salt Lake City, Utah area. Although the historical seismicity of central Utah around Salt Lake City is only moderate, there is some evidence of Holocene faulting and considerable evidence of pleistocene faulting. Because of this faulting, we have modeled the seismicity of north central Utah as a single zone including the larger shocks that occur in northern Utah in the zone containing Salt Lake City. Similar examples could be given for California.

In the central and eastern United States the relationship between the general tectonic setting and historical seismicity has guided us in the construction of seismic source zones. We believe the approach used leads to a more realistic representation of the hazard than of the source zones are constructed simply by enclosing isolated groups of earthquake epicenters.

It is obvious that the question of what constitutes optimum utilization of geological data in probabilistic hazard mapping admits of a wide range of interpretation. We have presented only one of a large number of interpretations of the data. There is a point of view that the primary indicator of seismic hazards ought to be the existence of Quaternary faulting. Several points should be noted. First, for use in probabilistic calculations, it is necessary to assign rates and magnitudes to earthquakes expected to occur on Quaternary faults. There are few faults for which recurrence rates have even been approximated. 
Second, the relevance of taulting to hazard depends on the level of hazard with which we are concerned. Just as it is possible to say that Holocene faulting is most significant, Pleistocene less so, and older faulting progressively less important (A11en, 1975) one may infer that the most recent historical activity is most important to the near future activity or for short recurrence intervals. The alleged fact that regions in China and Turkey possibly show long periods of activity and quiescence of the order of one or two thousand years suggests that using the historical experience of the last 100 years to generalize to the expected experience of the next 100 years will be correct 90 to 95 percent of the time. This conclusion depends upon restricting ourselves to short recurrence intervals. There will be great earthquakes with recurrences of 1,000 to 10,000 years whose recurrence cannot be estimated from the historical seismicity alone. The exceedance probabilities associated with these infrequent events is correspondingly small and for engineering purposes is relevant or irrelevant depending upon the acceptable risks. For nuclear reactors, earthfill dams, reservoirs with unstable slopes, etc. only very small risks (design exceedance probabilities) are tolerable, and long recurrence-interval earthquakes should define the design. For dwellings, commercial structures, etc., short recurrence-interval earthquakes should define the design and the historical record becomes more relevant. In practice, however, over much of the United States, it is the historical earthquakes that call attention to the fact that an earthquake hazard exists at all. If we relied only on evidence of Quaternary faulting, little or no hazard would be known in the Eastern United States. It is the lack of known 
Quaternary faulting in much of the United States that calls attention to the fact that we need to investigate the possibility of using a wide range of geological and geophysical data to understand the distribution of historical earthquakes, limit their provinces, establish their potential magnitudes, and estimate their recurrences. Extensive additional investigations of faulting in the United States, particularly Quaternary and younger faulting, are necessary before fault data can be properly used for the evaluation of hazard. We must, however, realize that evidence of faulting may be totally inadequate as a guide to the earthquake hazard over large areas of the country. Sensitivity to elemental assumptions

In this section, we indicate how the mapped accelerations are affected by changes of assumption or changes in input parameters. 1. Changing source boundaries. A comparison of the source zone boundaries and the acceleration contours shows that they often nearly coincide. This happens because a boundary generally marks a large change in seismic activity rate, and the acceleration attenuation functions are so steep as a function of distance that the shaking effects of the seismic activity do not propagate far into the neighboring, relatively non-seismic regions. The exceptions occur where seismic source zones overlay one another with not-so-strong contrasts in activity rates. In these cases, such as Puget Sound and the Wasatch Front area, the contours do not fall on source boundaries but are roughly concentric to them, as might be expected.

2. Changing seismic activity rate. Calculations of extreme probability accelerations for different return periods show that the follow- 
ing approximate rule-of-thumb applies;

$$
\mathrm{a}_{1} / \mathrm{a}_{2}=\left(\mathrm{T}_{1} / \mathrm{T}_{2}\right)^{\alpha}
$$

where $a_{1}, a_{2}$ are peak accelerations at a particular site for return periods $\mathrm{T}_{1}$ and $\mathrm{T}_{2}$, and $\alpha$ is such that for $\mathrm{a}_{1} / \mathrm{a}_{2}=2$, then $\mathrm{T}_{1} / \mathrm{T}_{2}=5$. (Thus, $\alpha=.43)$. It thus takes a relatively large change in return period in order to to double the mapped peak acceleration. Since return period is inversely proportional to the seismic activity rate the extreme probability accelerations are relatively insensitive to changes in seismic activity. As might be expected by the rule-of-thumb and the strong boundary effect cited above, the location of the contours is generally only weakly affected by changes in seismic activity rates.

As an example of a large contrast in rate, consider the fact that earthquakes in the Eastern United States occur roughly one-tenth as frequently as those in California. At relatively high levels of motion, this rate-ratio for the occurrence of earthquakes more or less corresponds to the rate-ratios of occurrences of the ground motions. Hence we would expect the ratio between peak accelerations for the active portions of California and those of the Eastern United States would be about:

$$
\mathrm{a}_{1} / \mathrm{a}_{2}=(10) \cdot 43=2.7
$$

Hence if $.6 \mathrm{~g}$ corresponds to the most active areas in California, we would expect the most active areas in the east to have peak acceleration 
values of

$$
0.6 / 2.7=.22 \mathrm{~g}
$$

Values near this size occur in the southeastern Missouri area.

On the other hand, consider what happens when the seismic activity rates are in the ratio, $\mathrm{T}_{1} / \mathrm{T}_{2}=2$. Now $\mathrm{a}_{1} / \mathrm{a}_{2}=(2)^{\cdot 43}=1.35$, so that doubling the activity rate in a source zone only increases the extreme motions by about a third. If a contour occurs at a place where the motion levels change by a factor of 2 over a short distance, then changing the zone seismic activity by a factor of 2 is unlikely to change the location of the contour. This kind of contrast at a contour boundary is mostly the case with isolated source zones where the activity is much greater than in the surrounding region. On the other hand, contour locations are most likely to move where source zones are superimposed and where the rates per unit area do not change much from zone to zone. Likely sensitive areas are thus Puget Sound and the Wasatch Front.

Figure 5 shows the results for a region in eastern Oklahoma and southeastern Kansas. This figure shows the results when all the seismic activity rates have been doubled. As expected, in comparison with the map values (fig. 4), there is little change in the contour locations and the values at corresponding locations between the contours. 3. Changing b-values (slopes of seismic activity vs magnitude curves). The most obvious effect of changing the b-value is to change the $\log \mathrm{N}$ vs $M$ curve for a source zone so that (if total numbers of earthquakes above the minimum magnitude remain the same) there are relatively fewer 
expected earthquakes at one end of the curve, rather more at the other end. From the discussion of the previous section, we expect that the effect on the map will be similarly small.

For the Kansas-Oklahoma case, the b-values were decreased by .20, roughly two standard deviations, with total expected earthquakes remaining the same but increasing the relative number of earthquakes at the high-magnitude end. As with the previous case, the effect is to change only a little the contour locations and the values at corresponding points between the contours (fig. 6).

4. Changing assumed maximum magnitude. It is to be expected that adopting a higher maximum magnitude and at the same time extrapolating linearly the $\log N$ vs $M$ curve to assign the corresponding number of occurrences, should have a significant effect on the map. These new, larger-magnitude earthquakes produce occurrences of motions, which at every point are larger than the previously calculated maximum motions. The ratio of new maximum motions to the previous maxima is greatest where the $\Delta M$-increase results in the largest change in acceleration. Inspection of the attenuation curves shows that this occurs at relatively low magnitudes, because the attenuation curves are increasingly closer together at the high magnitudes. Hence where we have previously assigned a low maximum magnitude, a $\Delta M$ increase produces a large change in maximum acceleration, but where we have previously assigned a high maximum magnitude, the same $\Delta M$ increase produces a small change in maximum acceleration. The resulting effect on the map, however, depends on the number of occurrences extrapolated for the new maximum magnitude earthquakes. If, for instance, the extrapolated number of occurrences 
Occurrence Rate Doubled
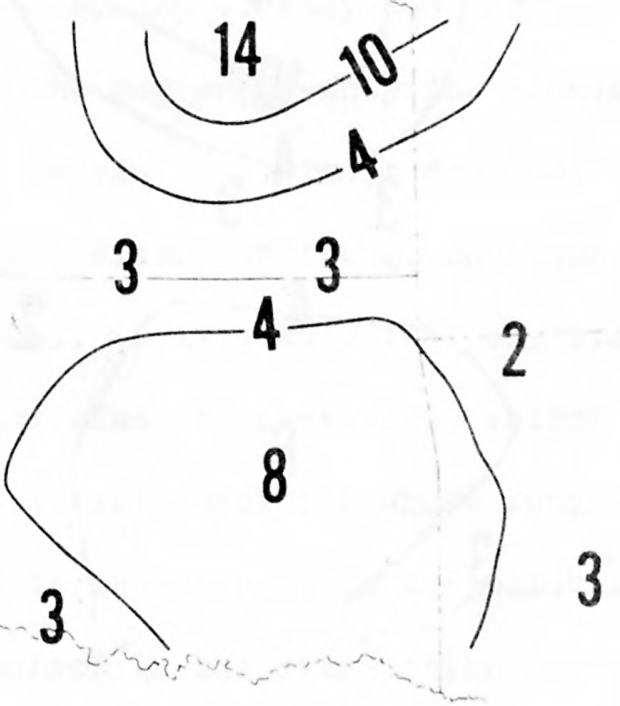

Figure 5.--Mapped accelerations resulting from a doubling of occurrence rate in all relevant source areas. 
- Value Increased $B y+0.2$
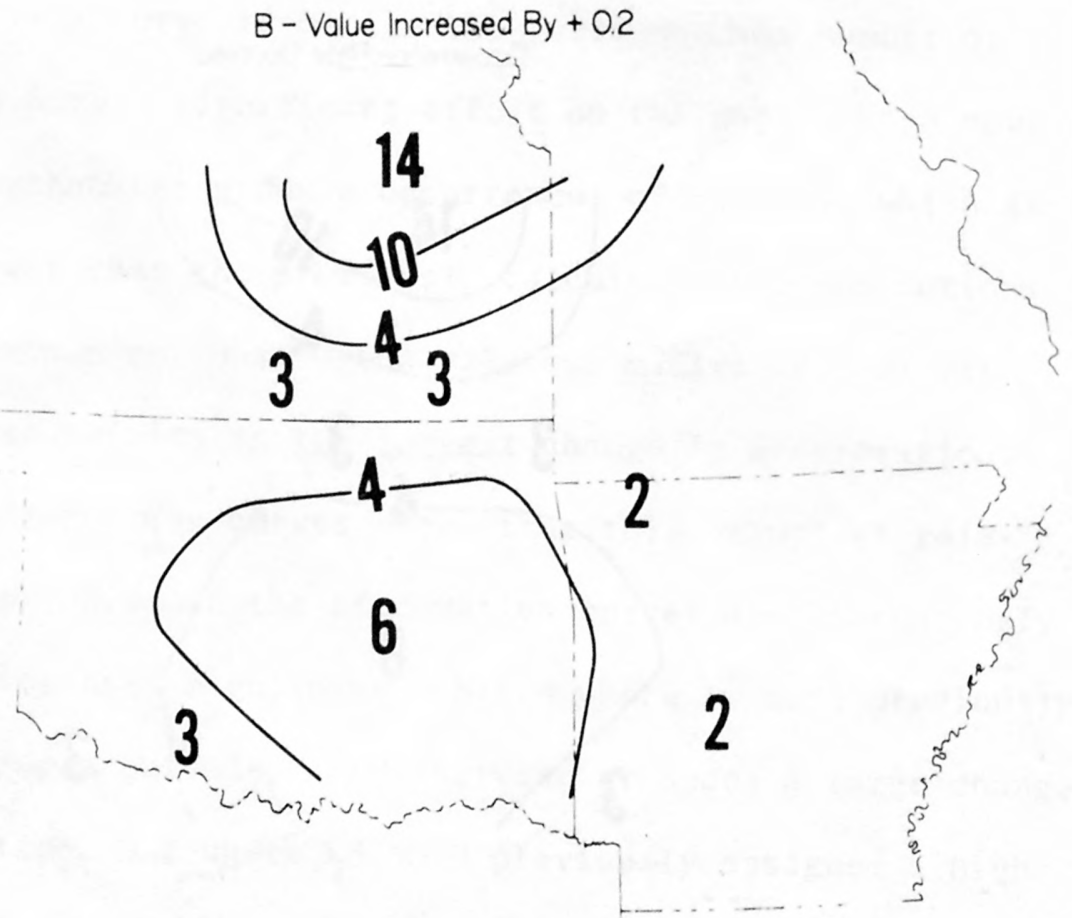

Figure 6.--Mapped accelerations resulting from an increase in $b$ values of +0.20 for the relevant source areas. 
at the new maximum magnitude is significantly smaller than a rate of 1 per 500 years (the return period of motions at this probability of exceedance), say 1 per 5,000 years, the results would not shift the acceleration distribution sufficiently to produce an important change at this probability level.

For the Kansas-Ok1ahoma area, figures 7 and 8 show the effect when the maximum magnitudes are increased by $\Delta M=0.6$ and 1.2 . In the first case, the results are much the same as doubling the seismicity. In the second case, the changes are more dramatic. Formerly "invisible zones" rise into contours, contours shift significantly in location, and there are relatively large changes in values between the contours. Not illustrated here is the case when a similar calculation was performed in the Idaho-western Wyoming-western Montana area. The effect was insignificant at those portions of the map already showing high motion levels, but at those portions of the map where only low acceleration extremes were plotted, the motion levels were almost doubled. 5. Attenuation function. Biases in the attenuation function will have a direct effect on the map. It is likely that any biases will be different for different magnitudes and distances, rather than a simple multiplicative factor applicable over the whole range of magnitudes and distances. Consequently it is not easy to definitively treat the problem by a single variation in the attenuation function, nor to anticipate the result by simple reasoning. It is possible to produce another map with a different attenuation function derived from principles other than those used by Schnabel and Seed (1973). We estimate that the important portion of an attenuation function for acceleration 
in active source regions is the relatively close-in region 10 to $50 \mathrm{~km}$ from the earthquake epicenter. An alternate set of curves would give similar results to those obtained from the Schnabel and Seed curves, to the extent that these two sets are similar in the region 10 to $50 \mathrm{~km}$. Differences in the curves closer than $10 \mathrm{~km}$ or further than $50 \mathrm{~km}$ are generally not significant. The exception is the case in which an active, large-magnitude-generating, fault requires the use of the finite template. Since in this case the acceleration on the map is given by the attenuation of the high magnitude event, near the fault the mapped acceleration depends directly on the appropriate peak accelerations within $10 \mathrm{~km}$. As strong motion recordings have not been observed in this region for large magnitude earthquakes, it is possible that these close-in accelerations may be significantly higher than the values given by Schnabel and seed.

Statistical variability in the attenuation functions (rather than zero variability in the Schnabel and Seed curves as we have used them) will produce somewhat larger accelerations on the map. An analysis of the effect of variability in the attenuation function on probabilistic hazard can be found in the work of Cornell and Vanmarke (1975). They show that for a standard deviation of 0.75 (corresponding roughly to a factor of 2 in the acceleration curves), the acceleration at a given return period is increased over the zero-variability case by about 25 percent.

6. Summary. From the discussion of the previous sections, it appears as though the details of determining the seismicity of zones are relatively unimportant in the determination of motion levels on this map. 
Upper Bound Magnitudes Increased + 06

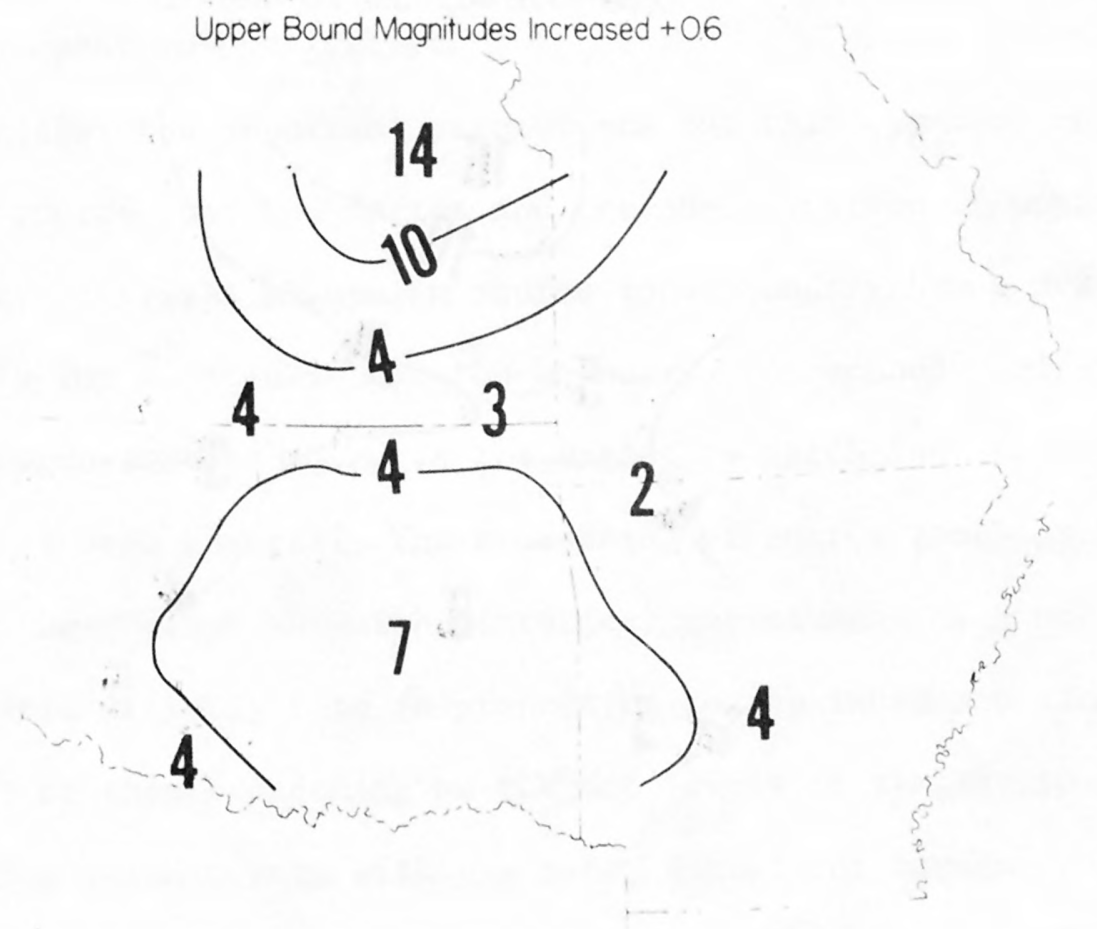

Figure 7.--Mapped accelerations resulting from an increase in upper bound magnitude of 0.6 for the relevant source areas. 
Upper Bound Magnitudes Increased + +2

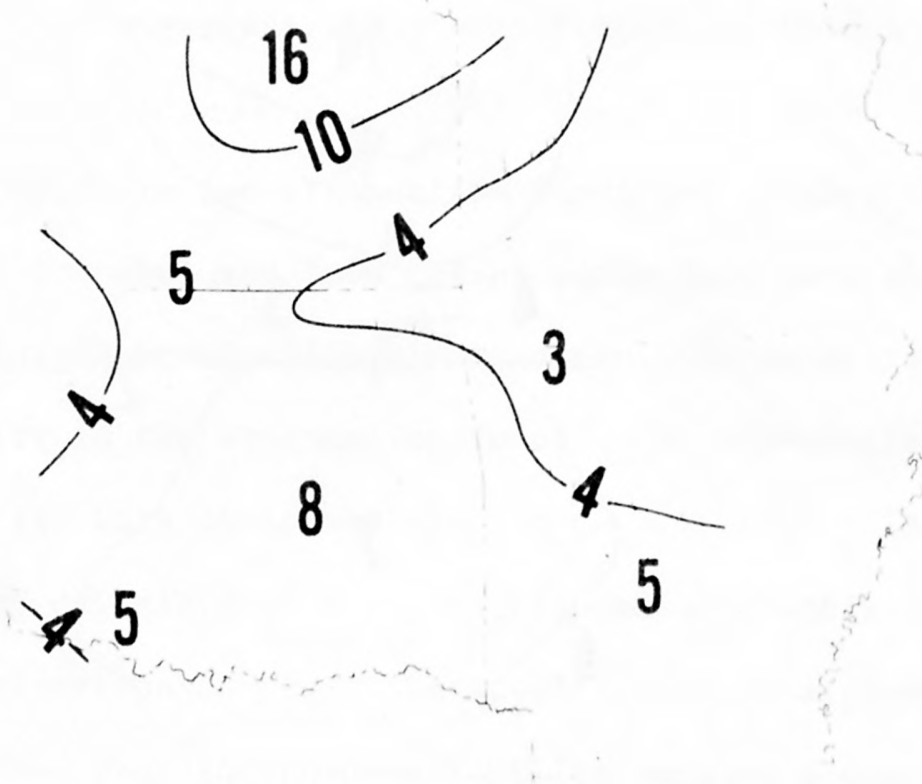

Figure 8.--Mapped accelerations resulting from an increase in upper bound magnitude of 1.2 for the relevant source areas. 
It must be emphasized that this is entirely due to the decision to display motion levels for a constant exceedance probability rather than to display exceedance probability for some constant level of motion. The flatness of the calculated acceleration vs return period relationships is the cause of the insensitivity of the contours to changes in seismic rates. Cornell (1968), in his analytical formulation, shows how the coefficient $\alpha$ depends upon the coefficient which specifies the nature of the magnitude dependence of peak acceleration and upon the bvalue of the $\log N$ vs $M$ relationship. In his hypothetical case $\alpha$ is .5 for acceleration vs return period (and .675 and .75 for peak velocity and peak displacement respectively).

It appears that the important assumptions for this map are the delineation of source-zone boundaries and the specification of upperbound magnitude. A slight change in source-zone boundary has a drastic effect--but only for locations near the boundary. A secondary effect of changing the source-zone boundary is the extent to which the seismic activity per unit area changes. The broadening of source zones away from the localized regions in which historical earthquakes have occurred lowers the seismic activity rate in proportion to the increased area. Thus the effect of this broadening on the map levels is similar to that of decreasing the seismic rate within a zone, except, of course, that contour locations are directly affected, while in the interior of the zone the motion levels change relatively slowly.

In only two areas of the United States is this broadening large. One is the extension of the activity occurring near a line running from 
Charleston, South Carolina, northwest towards Knoxville, Tennessee. The present source zone covers South Carolina and extends into Georgia. The area of this zone would have to be narrowed by a factor of 5 in order to increase the plotted motion level by a factor of 2 (using the rule-ofthumb). The other area of extension is that which takes the historical activity primarily at the northern end of the wasatch Front and distributes it evenly along the entire, recently-active portion of the front. In this case the area of the hypothetical source region has increased significantly from the area in which the strongest historical earthquakes have occurred.

It can also be surmised, from the acceleration vs return period rule-of-thumb and rough considerations of the areas involved, that an attempt to produce an acceleration map of the Eastern United States by a uniform distribution of all historical seismicity east of the Rocky Mountains would result in a uniform motion level between 4 and 10 percent g. Such a map would emphasize the hypothesis that earthquakes could happen anywhere in the Eastern United States, but the motion levels as design motions are probably easily met by structures conforming to wind-loading codes--earthquake protection would not be a design criterion at a11.

The determination of the maximum magnitude for a source zone is a difficult problem. In many cases, there is no satisfactory solution other than personal preference. In regions in which faults are prominent, the activity is also usually large enough that near-maximum magnitudes are often present in the historical record. In this case, 
there is not likely to be a discrepancy in choosing a maximum magnitude for a large and active source region between the maximum observed value and a magnitude-fault length regression value for the longest fault.

Where there are prominent large faults but little activity, it is reasonable to assume a maximum magnitude based on a fault length-magnitude regression from some other region.

The difficulty in assigning maximum magnitudes is most acute where there are no faults known, and especially where there is low seismicity and thus where near-maximum magnitude earthquakes may not have been experienced in the historical record. This is true for virtually the entire Eastern United States (with the exception of the New Madrid and Charleston areas), the Puget Sound area, and inactive portions of the Rocky Mountains.

One can invent reasons why one should use maximum magnitudes less than, the same as, or larger than those maximum magnitude earthquakes observed. For example, if most eastern earthquakes are aftershocks, of large, prehistoric earthquakes of long recurrence time, or no recurrence, then future earthquakes in these regions are likely to be the same size or smaller than those historically experienced, depending on how rapidly the aftershock sequence is tailing off. If, on the other hand, one believes that where there are mainshocks, or aftershocks, there will again be mainshocks of short recurrence time or aftershocks of slow decay time, one would be justified in assuming future earthquakes of magnitudes equal to or larger than those maximum magnitudes experienced historically. In the absence of a tectonic reason for the 
location of earthquakes, and in the absence of physical correlatives to judge the maximum sizes possible, it is difficult to choose between these assumptions. The use of observed maximum magnitudes (or intensities) is common to both assumptions. Our assumption of maximum magnitudes equal to those observed historically is not conservative in the Great Plains region (it is somewhat less important in other regions) 
The probabilistic acceleration map presented here should be considered as a mapping of one parameter of ground motion resulting from the assumption of a particular model of earthquake occurrence and ground motion attenuation. The usefulness of the map is not so much in the absolute values of acceleration mapped but primarily because it provides insight into the relative hazard across the United States together with results concerning the relative importance of the various parameters involved.

We see from analysis of the model that the following generalizations are valid:

1. The severity of ground motion does not depend critically upon the seismic source zone boundaries except near the zone boundaries.

2. The severity of ground motion depends heavily on the maximum magnitude earthquake assumed for the seismic source zone if the level of seismicity in the zone is fairly high and the historically observed maximum is low. If the level of seismicity in the seismic source area is low and the historical maximum is high, the maximum magnitude assumption is much less critical. Another way of looking at this is to say that if at some site the rapped acceleration is low, it is likely that increasing the maximum magnitude for the nearest zones will produce a dramatic increase of the mapped values. If, on the other hand, the mapped acceleration is high, it is unlikely that increasing the maximum magnitude will have a further important effect. 
3. For probabilistic hazard-type calculations, differences in results for two different attenuation functions are much less dramatic than for deterministic-type calculations. Because the largest number of occurrences of high accelerations comes from a band about the site, for probabilistic calculations, the two attenuation-functions need only have roughly the same values in the distance range 10 to $50 \mathrm{~km}$ in order to produce comparable results.

4. The accelerations mapped near faults in areas of high seismicity with known occurrences of shocks of large magnitude (such as along the San Andreas fault) depend on the nature of the acceleration attenuation curves for large earthquakes at close distances. Changes in attenuation for large shocks at close distances will have a considerable effect on the hazard in these areas.

5. The acceleration values in the Puget Sound area depend upon the assumption that large earthquakes will occur only at depths of about 40-60 km. If large shallow shocks are considered reasonable, the hazard becomes much greater.

The map prepared as an end product of this study represents a first attempt, to estimate probabilistic hazard on a national basis using a simple model. Hopefully it will serve as a reference for the development of more sophisticated models and will stimulate development of maps of other ground motion parameters besides acceleration. 


\section{ACKNOWLEDGEMENTS}

We wish to acknowledge the contribution of and thank

William Isherwood for his revision of the earthquake catalogs in the Northern Rockies and the Basin and Range States, his pro duction of the hazard map in the Northern Rockies, and his supervision of the computation in the Eastern United States;

Bernice Bender of the Bureau of Standards in Boulder, Colorado, for implementing the computer program and assisting in its design;

Karen Spencer for operating the program, maintaining the data files, and plotting the results;

Gary Lundquist for revising the New England catalog;

Professors Allin Cornell and R. V. Whitman for support and encouragement;

Reva Tibbetts for the typing of the report in its many drafts and revisions.

The mathematical development of the elementary extreme value theory on p. 6 follows that presented by Prof. Leon Borgman (now at the University of Wyoming) in a course on risk statistics given at the University of California, Berkeley, in 1970 . 
Algermissen, S. T., 1969, Seismic Risk Studies in the United States, World Conf. of Earthquake Engineering, 4th, Proceedings, v. 1, p. $14-27$.

Algermissen, S. T., and Perkins, D. M., 1972, A technique for seismic zoning: General considerations and parameters, Proc. of the Int 1. Conf. on Microzonation, Seattle, Washington, p. 865-878.

Algermissen, S. T., and Perkins, D. M., 1976, Seismic risk evaluation of the Balkan region, UNESCO, p. 18-19.

Algermissen, S. T., Stepp, J. C., Rinehart, W. A., and Arnold, E. P., 1969, Studies in seismicity and earthquake damage statistics:

ESSA, U.S. Dept. Commerce, Appendix B, 68 p.

Allen, Clarence R., 1975, Geological criteria for evaluating seismicity, Seismol. Soc. America Bu11., v. 86, p. 1041-1057.

Applied Technology Council, San Francisco, California, 1976, Working draft of recommended comprehensive seismic design provisions for buildings.

Bollinger, G. A., 1973, Seismicity of the southeastern United States Seismo1. Soc. America Bu11., v. 63, p. 1785-1808.

Bonilla, M. G., 1967, Historic surface faulting in continental United States and adjacent parts of Mexico, U.S. Geological Survey OpenFile Rept., 36 p.

Corne11, C. A., 1968, Engineering seismic risk analysis: Seismol. Soc. America Bu11., v. 58, p. 1583-1606.

Corne11, C. Allin, and Vanmarke, E. H., 1969, The major influences on seismic risk: World Conf. of Earthquake Engineering, 4th, Proceedings, Santiago, Chile, p. 69-83.

1975, Seismic risk analysis for offshore structures: 1975 Offshore Technology Conference, Houston, $8 \mathrm{p}$.

Diment, W. H., Urban, T. C., and Revetta, R. A., 1972, Some geophysical anomalies in the eastern United States, in Robertson, E. C. ed., The Nature of the Solid Earth, New York, McGraw-Hi11, p. 544-574.

Fischer, J. A. and McWhorter, J. A., 1972, The microzonation of New York State, Proc. of the Int1. Conf. on Microzonation for Safer Construction-Research and Application, v. 1, p. 283-295. 
Fox, F. L., 1970, Seismic geology of the eastern United States, Assn. Engr. Geol. Bul1., v. 7, p. 21-43.

Gutenberg, B. and Richter, C. F., 1956, Earthquake magnitude, intensity, energy and acceleration, Seismol. Soc. America Bul1., v. 32, p. $163-191$.

Hays, W. W., Algermissen, S. T., Espinosa, A. F., Perkins, D. M., and Rinehart, W. A., 1975, Guidelines for developing design earthquake response spectra: Construction Eng. Research Lab., Tech. Rept. M$114, \mathrm{p}$.

Hintze, L. F., 1972, The Wasatch fault zone east of Provo, Utah, in Enviromental Geology of the Wasatch front, 1971, Utah Geological Assn. pub. 1-F, $10 \mathrm{p}$.

Hopper, M. G., Langer, C. J., Spence, W. J., Rogers, A. M., and Algermissen, S. T. (geological and seismological portions); Olsen, B. C., Lagorio, H. J., and Steinbrugge, K. V. (engineering analysis portion), 1975, A study of earthquake losses in the Puget Sound, Washington, area, U.S. Geol. Survey Open-File Rept. 75-375.

Kahle, James E. (Compiler) 1971, Provisional fault map of California, Calif. Div. of Mines and Geol., 1:1,000,000.

King, P. B., 1969, Tectonic map of North America, 1:1,000,000.

Leblanc, G., Wetmi1ler, R. J., Stevens, A. E., and Du Berger, R., 1971, Microseismic survey of the St. Lawrence Valley near La Malbaie, Quebec (abs): Earthquake Notes, v. 42, p. 16.

Liu, S. C. and De Capua, N. J., 1975, Microzonation of Rocky Mountain States, Proc. U.S. National Conf. on Earthquake Engr., 1975, p. $128-135$.

Milne, W. G. and Davenport, A. G., 1969a, Earthquake probability, Proc. Fourth World Conf. on Earthquake Engr., Santiago, Chile, v. 1, p. 55-68.

, 1969b, Distribution of earthquake risk in Canada, Seismol. Soc. America Bul1., v. 59, p. 729-754.

Morisawa, M., 1972, The Wasatch fault zone-general aspects, Utah Geol. Assn. Pub1. 1-D, p. D1-D17.

Nutt1i, 0. W., 1973, Design earthquakes for the Central United States, Misc. Paper S-73-1, U.S. Army Waterways Experiment Station, Vicksburg, Mississippi, $45 \mathrm{p}$. 
O1iver, J., Johnson, T., and Dorman, J., 1970, Post-glacial faulting and seismicity in New York and Quebec, Canadian Jour. Earth Sci., v. $7, \mathrm{p}, 579-590$.

Prowe11, D. C., O'Connor, B. J., and Rubin, M., 1975, Preliminary evidence for Holocene movement along the Belair fault zone near Augusta, Georgia, U.S. Geological Survey Open-File Rpt. 75-680, 8 p.

Richter, C. F., 1959, Seismic regionalization, Seismol. Soc. America Bul1., v. 49, p. 123-162.

Rikitake, T., 1975, Statistics of ultimate strain of the earth's crust and probability of earthquake occurrence, Tectonophysics, $v$. 26 , p. 1-21.

Roberts, E. B. and U1rich, F. P., 1950, Seismological activities of the Coast and Geodetic Survey in 1946, Seismol. Soc. America Bu11., v. 40, p. 195-216.

Ryal1, A., S1emmons, D. B., and Gedney, L. D., 1966, Seismicity, tectonism and surface faulting in the Western United States, Seismol. Soc. America Bul1., v. 56, no. 5, p. 1105-1135.

Sbar, M. L. and Sykes, L. R., 1973, Contemporary compressive stress and seismicity in Eastern North America: An example of intra-plate tectonics, Geo1. Soc. America Bul1., v. 84, p. 1861-1882.

Schnabe1, P. B. and Seed, H. B., 1973, Accelerations in rock for earthquakes in the Western United States, Seismol. Soc. America Bu11., v. 63, p. 501-516.

Seed, H. B., Murarka, R., Lysmer, J., and Idriss, I. M., 1975, Relationships between maximum acceleration, maximum velocity, distance from source and local site conditions for moderately strong earthquakes: College Eng., Calif. Univ. Berkeley, Calif., Rept. no. EERC 75-17, $36 \mathrm{p}$.

Smith, W. E. T., 1962, Earthquakes of Eastern Canada and adjacent areas, 1534-1927: Dominion Observatory, Ottawa, Pub., v. 26, p. 271-301.

1966, Earthquakes of Eastern Canada and adjacent areas, 19281959, Dominion Observatory, Ottawa, Pub., v. 32, p. 37-121.

Stepp, J. C., 1971, An investigation of earthquake risk in the Puget Sound area by use of the Type I distribution of largest extremes, Pennsylvania State University, Ph. D. Dissertation, $131 \mathrm{p}$. 
Suppe, J. Powe11, C., and Berry, R., 1975, Regional topography, seismicity, Quaternary vulcanism, and present-day tectonics of the Western United States, Am. J. Science, 275-A, p. 397-436.

U.S. Geological Survey and Am. Assoc. of Petrol. Geol., 1962, Tectonic map of the United States, 1:2,500,000.

Wiggins, J. H., Hirshberg, J. L., and Bronowicki, 1974, Budgeting justification for earthquake engineering research: Tech. Rept. No. 75-1201-1, National Science Foundation, 113 p.

Woollard, G. P., 1969, Tectonic activity in North America as indicated by earthquakes, Am. Geophys. Union Monog. 13, p. 125-133. 